\title{
Circulation
}

American

Heart

Association $_{\circledast}$

\section{Maintenance of Long-Term Clinical Benefit With Sirolimus-Eluting Coronary Stents : Three-Year Results of the RAVEL Trial}

Jean Fajadet, Marie-Claude Morice, Christoph Bode, Paul Barragan, Patrick W. Serruys, William Wijns, Constantino R. Constantini, Jean-Léon Guermonprez, Hélène Eltchaninoff, Didier Blanchard, Antonio Bartorelli, Gert-Jan Laarman, MarcoAntonio Perin, J. Eduardo Sousa, Gerhard Schuler, Ferenc Molnar, Giulio Guagliumi, Antonio Colombo, Ernesto Ban Hayashi and Egon Wülfert

Circulation. 2005;111:1040-1044; originally published online February 21, 2005; doi: 10.1161/01.CIR.0000156334.24955.B2

Circulation is published by the American Heart Association, 7272 Greenville Avenue, Dallas, TX 75231

Copyright $\odot 2005$ American Heart Association, Inc. All rights reserved.

Print ISSN: 0009-7322. Online ISSN: 1524-4539

The online version of this article, along with updated information and services, is located on the World Wide Web at:

http://circ.ahajournals.org/content/111/8/1040

Data Supplement (unedited) at:

http://circ.ahajournals.org/content/suppl/2005/02/27/01.CIR.0000156334.24955.B2.DC1.html

\begin{abstract}
Permissions: Requests for permissions to reproduce figures, tables, or portions of articles originally published in Circulation can be obtained via RightsLink, a service of the Copyright Clearance Center, not the Editorial Office. Once the online version of the published article for which permission is being requested is located, click Request Permissions in the middle column of the Web page under Services. Further information about this process is available in the Permissions and Rights Question and Answer document.
\end{abstract}

Reprints: Information about reprints can be found online at: http://www.lww.com/reprints

Subscriptions: Information about subscribing to Circulation is online at: http://circ.ahajournals.org//subscriptions/ 


\title{
Maintenance of Long-Term Clinical Benefit With Sirolimus-Eluting Coronary Stents Three-Year Results of the RAVEL Trial
}

\author{
Jean Fajadet, MD; Marie-Claude Morice, MD; Christoph Bode, MD; Paul Barragan, MD; \\ Patrick W. Serruys, MD; William Wijns, MD; Constantino R. Constantini, MD; \\ Jean-Léon Guermonprez, MD; Hélène Eltchaninoff, MD; Didier Blanchard, MD; \\ Antonio Bartorelli, MD; Gert-Jan Laarman, MD; MarcoAntonio Perin, MD; J. Eduardo Sousa, MD; \\ Gerhard Schuler, MD; Ferenc Molnar, MD; Giulio Guagliumi, MD; Antonio Colombo, MD; \\ Ernesto Ban Hayashi, MD; Egon Wülfert, BPharm
}

Background-The use of sirolimus-eluting coronary stents has been associated with a nearly complete elimination of restenosis at 6 months and with a very low 1-year incidence of major adverse cardiac events (MACE). This analysis examined whether these beneficial effects persist over the longer term.

Methods and Results - This multicenter trial randomly assigned 238 patients to revascularization of single, de novo, native coronary artery lesions with sirolimus-eluting versus conventional bare-metal stents. Survival free from target lesion revascularization (TLR), target vessel failure (TVF), and MACE up to 3 years of follow-up was compared between the 2 treatment groups. Complete data sets were available in $94.2 \%$ of patients treated with sirolimus-eluting stents and in $94.1 \%$ of patients randomized to the control group. The cumulative 1-, 2-, and 3-year event-free survival rates were $99.2 \%, 96.5 \%$, and $93.7 \%$ for TLR and $95.8 \%, 92.3 \%$, and $87.9 \%$ for TVF, respectively, in the sirolimus-eluting stent group, versus $75.9 \%, 75.9 \%$, and $75.0 \%$ for TLR and $71.2 \%, 69.4 \%$, and $67.3 \%$ for TVF in the control group $(P<0.001$ for both comparisons at 3 years). Rates of MACE at 3 years were $15.8 \%$ in patients randomly assigned to sirolimus-eluting stents versus $33.1 \%$ in patients assigned to bare-metal stents $(P=0.002)$. One patient treated with a sirolimus-eluting stent died of a cardiac cause between 12 and 36 months.

Conclusions - Treatment of de novo coronary stenosis with sirolimus-eluting stents was associated with a sustained clinical benefit and very low rates of TLR and of other MACE up to 3 years after device implantation. (Circulation. 2005;111:1040-1044.)

Key Words: stents $\square$ sirolimus $\boldsymbol{\square}$ restenosis $\boldsymbol{\square}$ coronary disease $\boldsymbol{\square}$ follow-up studies

$\mathrm{T}_{\mathrm{n}}^{\mathrm{n}}$ he inclusion of stents in a large percentage of percutaneous coronary revascularization procedures has fueled vigorous investigative efforts focused on the prevention of in-stent restenosis. Among the various strategies explored, the development of drug-eluting stents has been particularly promising. ${ }^{1}$ Stents coated with sirolimus (rapamycin), a macrolide antifungal agent with antiproliferative and immunosuppressant properties that inhibits regulators of cell-cycle progression and migration of vascular smooth muscle cells, ${ }^{2-4}$

\begin{tabular}{l} 
See p 958 \\
\hline effectively prevented the development of neointimal proliferation \\
and injury-induced arterial intimal thickening in preclinical stud- \\
ies $^{5-8}$ and that of in-stent restenosis in human pilot studies. \\
Furthermore, in randomized trials comparing sirolimus-eluting with $^{\text {conventional bare-metal stents, very low rates of in-stent restenosis }}$ \\
were observed at 6 to 8 months of follow-up in the groups treated \\
with drug-eluting stents. ${ }^{10-13}$ These remarkable angiographically
\end{tabular}

Received June 8, 2004; revision received October 19, 2004; accepted October 22, 2004.

From the Clinique Pasteur, Toulouse, France (F.J.); Institut Cardiovasculaire Paris Sud, Massy, France (M.-C.M.); Albert-LudwigsUniversitätskliniken, Kardiologie, Freiburg, Germany (C.B.); Clinique Beauregard, Marseille, France (P.B.); Thoraxcentrum, Rotterdam, the Netherlands (P.W.S.); Onze Lieve Vrouw Ziekenhuis, Cardiologie Intervasculair, Aalst, Belgium (W.W.); Clinica Cardiológyca C. Constantini, Curitiba, Paraná, Brazil (C.R.C.); Hôpital Broussais, Paris, France (J.-L.G.); Centre Hospitalier Universitaire de Rouen, Service de Cardiologie, Rouen, France (H.E.); Clinique Saint-Gatien, Tours, France (D.B.); Centro Cardiologico Monzino, Servizio Emodinamica, Milano, Italy (A.B.); OLVG Hospital, Department of Cardiology, Amsterdam, the Netherlands (G.-J.L.); The Heart Institute-Incor of the University Hospital of Sao Paulo, Sao Paulo, Brazil (M.P.); Institute Dante Pazzanese of Cardiology, Sao Paulo, Brazil (J.E.S.); Herzzentrum, Leipzig, Germany (G.S.); Semmelweis Egyetem Egészégtudomanyi Kar, Budapest, Hungary (F.M.); Azienda Ospedali Riuniti di Bergamo, Bergamo, Italy (G.G.); Centre Cuore Columbus, Milano, Italy (A.C.); Instituto Nacional de Cardiologia, Mexico City, Mexico (E.B.H.); and Cordis Clinical Research Europe, Waterloo, Belgium (E.W.).

The online-only Data Supplement can be found with this article at http://www.circulationaha.org.

Correspondence to Jean Fajadet, MD, Clinique Pasteur, 45, Avenue du Lombez, 31300 Toulouse, France. E-mail fajadet@interv-cardiol-toul.com

(C) 2005 American Heart Association, Inc. 
documented results were corroborated by very low rates of major adverse cardiac events (MACE) at 1 year. ${ }^{10}$

The purpose of this analysis was to examine whether this favorable effect on clinical events observed in the RAVEL trial (Randomized Study with the Sirolimus-Coated Bx Velocity Balloon-Expandable Stent in the Treatment of Patients with de Novo Native Coronary Artery Lesions) persisted beyond 1 year.

\section{Methods}

\section{Patient Selection}

The design and detailed methods of this randomized, double-blind clinical trial have been published previously. ${ }^{10}$ In brief, the 238 randomized patients had stable or unstable angina pectoris ${ }^{14,15}$ or silent ischemia caused by a single de novo coronary lesion $(51 \%$ to $99 \%$ diameter stenosis) in a vessel between 2.5 and $3.5 \mathrm{~mm}$ in diameter. Major exclusion criteria included evolving myocardial infarction, $a \geq 50 \%$ stenosis in an unprotected left main coronary artery, an ostial target lesion, a calcified lesion that could not be successfully predilated with an angioplasty balloon, or an angiographically visible thrombus within the target lesion.

The study was reviewed and approved by each participating institution's Ethical Review Committee, and all patients signed a written informed consent before enrollment.

\section{Study Procedures}

After successful predilatation of the target lesion, patients were randomly assigned 1:1 in a double-blind manner to a conventional bare-metal Bx Velocity balloon-expandable stent or a sirolimuseluting, Cypher balloon-expandable stent (Cordis Corp, Johnson \& Johnson). Postdilatation was performed as necessary. Procedural success was defined as attainment of a $<30 \%$ vessel diameter stenosis and freedom from in-hospital MACE after implantation of the assigned study device.

\section{Patient Follow-Up}

Patients returned for yearly follow-up evaluations to monitor the possible interim development of angina or MACE. Follow-up angiography with quantitative coronary angiography was performed systematically at $180 \pm 30$ days as described previously. ${ }^{10}$ Because of the double-blind nature of the study, the decision to perform further target lesion or vessel revascularization after the 6-month angiographic follow-up was left to the investigator's discretion, by protocol design.

\section{Study End Points and Definitions}

The primary angiographic end point of the trial was in-stent late luminal loss at 6 months, ascertained by quantitative coronary angiography. ${ }^{10}$ The primary clinical end point of the study was a composite of MACE at 6 months, defined as cardiac or noncardiac death, Q-wave and non-Q-wave myocardial infarction, coronary artery bypass graft, or target lesion revascularization (TLR). A TLR was adjudicated as being "clinically driven" by the independent Clinical Events Committee on the basis of the presence of a $>50 \%$ diameter stenosis on the 6-month angiogram in the presence of signs or symptoms of myocardial ischemia or a $>70 \%$ diameter stenosis in the absence of ischemia. Target-vessel failure (TVF) was defined as any revascularization of the index vessel, myocardial infarction, or death that could not be unequivocally attributed to a vessel other than the index vessel.

\section{Statistical Analyses}

All analyses were based on the intention-to-treat principle. For continuous variables, differences between the treatment groups were evaluated by ANOVA or Wilcoxon's rank-sum test. For discrete variables, differences were expressed as counts and percentages and were analyzed with Fisher's exact test. Revascularization of the
TABLE 1. Baseline Clinical and Angiographic Characteristics of Overall Patient Population and Each Study Group

\begin{tabular}{|c|c|c|c|}
\hline & \multicolumn{3}{|c|}{ Sirolimus-Eluting } \\
\hline & $\begin{array}{l}\text { All Patients } \\
(n=238)\end{array}$ & $\begin{array}{c}\text { Stents } \\
(\mathrm{n}=120)\end{array}$ & $\begin{array}{l}\text { Controls } \\
(n=118)\end{array}$ \\
\hline Mean age, y & $60.7 \pm 10.4$ & $61.8 \pm 10.7$ & $59.7 \pm 10.1$ \\
\hline Men & 76 & 70 & $81 \ddagger$ \\
\hline Previous Ml & 36 & 38 & 34 \\
\hline Diabetes mellitus & 19 & 16 & 21 \\
\hline Treated hypercholesterolemia & 40 & 38 & 43 \\
\hline Treated hypertension & 61 & 62 & 61 \\
\hline Current smoker & 30 & 27 & 33 \\
\hline \multicolumn{4}{|l|}{ Angina pectoris } \\
\hline Unstable* & 51 & 48 & 52 \\
\hline Stable† & 38 & 41 & 37 \\
\hline Silent ischemia & 11 & 11 & 11 \\
\hline \multicolumn{4}{|l|}{ Target coronary artery } \\
\hline LAD & 50 & 49 & 51 \\
\hline $\mathrm{RCA}$ & 27 & 27 & 27 \\
\hline $\mathrm{LCx}$ & 23 & 24 & 22 \\
\hline \multicolumn{4}{|l|}{ Lesion type } \\
\hline A & 7 & 8 & 4 \\
\hline B1 & 37 & 39 & 35 \\
\hline B2 & 57 & 54 & 61 \\
\hline Reference vessel diameter, mm & $2.62 \pm 0.53$ & $2.60 \pm 0.54$ & $2.64 \pm 0.52$ \\
\hline Lesion length, mm & $9.58 \pm 3.25$ & $9.56 \pm 3.33$ & $9.61 \pm 3.18$ \\
\hline
\end{tabular}

$\mathrm{MI}$ indicates myocardial infarction; RCA, right coronary artery; and LCX, left circumflex artery. Values are mean \pm SD or percentage of patients.

*Unstable angina was defined according to the system of Braunwald. ${ }^{15}$

†Stable angina was defined according to the system of the Canadian Cardiovascular Society. ${ }^{14}$

$\ddagger P=0.05$ vs sirolimus-eluting stents; all other between-groups differences are statistically nonsignificant.

target lesion or vessel and the composite of MACE during follow-up were analyzed by the Kaplan-Meier method. Differences between the event-free survival curves for the 2 groups were compared by use of the Wilcoxon and log-rank tests. A 2-sided probability value of $P<0.05$ was considered statistically significant.

\section{Results}

The baseline clinical characteristics of the RAVEL trial population have been described in detail previously ${ }^{10}$ and are summarized in Table 1. Except for a significantly higher percentage of men in the group treated with bare-metal stents, the 2 study groups were similar with respect to all variables examined. Complete data sets were available at 3 years in $94.2 \%$ of patients randomly assigned to sirolimus-eluting stents and in $94.1 \%$ of patients randomized to the control group. The number and percentages of patients who experienced a MACE (Cypher, 15.8\%, versus Bx Velocity, 33.1\%) through 3 years of follow-up are listed in hierarchical order in Table 2, top, and nonhierarchical order in Table 2, bottom. The incidence of MACE was significantly lower in the recipients of sirolimus-eluting stents than in patients assigned to conventional bare-metal stents. This lower MACE rate was attributable primarily to fewer TLR procedures performed in 
TABLE 2. MACE Recorded Up to 3 Years in the Actively Treated (Sirolimus) vs the Control Group

\begin{tabular}{|c|c|c|c|}
\hline & $\begin{array}{l}\text { Sirolimus } \\
(\mathrm{n}=114)^{\star}\end{array}$ & $\begin{array}{l}\text { Controls } \\
(\mathrm{n}=113)^{\star}\end{array}$ & $P$ \\
\hline \multicolumn{4}{|l|}{ Hierarchical order } \\
\hline Death & $9(7.9)$ & $5(4.4)$ & NS \\
\hline Cardiac & $1(0.9)$ & $3(2.7)$ & NS \\
\hline Noncardiac & $8(7.0)$ & $2(1.8)$ & NS \\
\hline Nonfatal MI & $4(3.5)$ & $6(5.3)$ & NS \\
\hline Q-wave & $3(2.6)$ & $2(1.8)$ & NS \\
\hline Non-Q-wave & $1(0.9)$ & $4(3.5)$ & NS \\
\hline All TLR & $6(5.3)$ & $28(24.8)$ & $<0.001$ \\
\hline Surgical & $2(1.8)$ & $1(0.9)$ & NS \\
\hline Percutaneous & $4(3.5)$ & $27(23.9)$ & $<0.001$ \\
\hline Clinically driven TLR & $5(4.4)$ & $16(14.2)$ & 0.012 \\
\hline Surgical & $2(1.8)$ & 0 & NS \\
\hline Percutaneous & $3(2.6)$ & $16(14.2)$ & 0.002 \\
\hline All MACE & $19(16.7)$ & $39(34.5)$ & 0.002 \\
\hline \multicolumn{4}{|l|}{ Nonhierarchical order } \\
\hline Death & $9(7.9)$ & $5(4.4)$ & NS \\
\hline Cardiac & $1(0.9)$ & $3(2.7)$ & NS \\
\hline Noncardiac & $8(7.0)$ & $2(1.8)$ & NS \\
\hline Ml & $6(5.3)$ & $8(7.1)$ & NS \\
\hline Q-wave & $3(2.6)$ & $3(2.7)$ & NS \\
\hline Non-Q-wave & $3(2.6)$ & $5(4.4)$ & NS \\
\hline All TLR & $7(6.1)$ & $29(25.7)$ & $<0.001$ \\
\hline Surgical & $3(2.6)$ & $1(0.9)$ & NS \\
\hline Percutaneous & $5(4.4)$ & $28(24.8)$ & $<0.001$ \\
\hline Clinically driven TLR & $6(5.3)$ & $17(15.0)$ & 0.016 \\
\hline Surgical & $3(2.6)$ & 0 & NS \\
\hline Percutaneous & $4(3.5)$ & $17(15.0)$ & 0.003 \\
\hline Target vessel revascularization $†$ & $2(1.8)$ & $3(2.7)$ & NS \\
\hline $\begin{array}{l}\text { Target vessel failure } \\
\text { (clinically driven target vessel } \\
\text { revascularization) }\end{array}$ & $12(10.5)$ & $27(23.9)$ & 0.008 \\
\hline $\begin{array}{l}\text { Target vessel failure (all target } \\
\text { vessel revascularization) }\end{array}$ & $13(11.4)$ & $38(33.6)$ & $<0.001$ \\
\hline
\end{tabular}

$\mathrm{Ml}$ indicates myocardial infarction; MACE indicates any death, MI, or TLR; and target vessel failure indicates cardiac death, MI, or TVR. Values indicate numbers (\%) of patients.

${ }^{*} \mathrm{n}=$ all collected 3-year follow-up data + patients with MACE event. †For lesions other than the target lesion.

the sirolimus-eluting stent patients. The cumulative 1-, 2-, and 3-year survival rates free from TLR were, respectively, $99.2 \%, 96.5 \%$, and $93.7 \%$ in the group randomized to sirolimus-eluting stents, versus $75.9 \%, 75.9 \%$, and $75.0 \%$ in the control group (log-rank $P<0.001$; Wilcoxon $P<0.001$; Figure 1). Similarly, the cumulative 1-, 2-, and 3-year survival rates free from TVF were, respectively, 95.8\%, $92.3 \%$, and $87.9 \%$ in the group randomized to sirolimuseluting stents, versus $71.2 \%, 69.4 \%$, and $67.3 \%$ in the control group (log-rank $P<0.001$; Wilcoxon $P<0.001$; Figure 2). Finally, the corresponding cumulative MACE-free survivals were $94.1 \%, 88.3 \%$, and $83.7 \%$ in the sirolimus-eluting stent
Survival Free from Target Lesion Revascularization

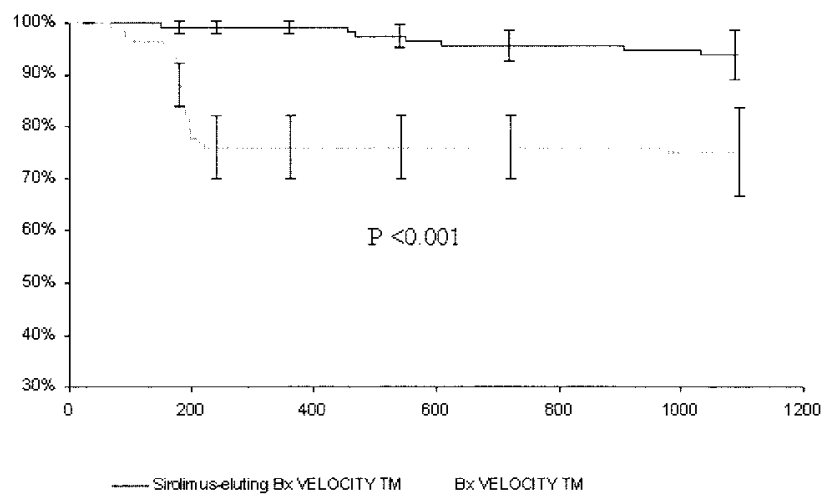

Figure 1. Survival free from TLR in the sirolimus-eluting stent group (dark line) and the control group (shaded line). Error bars $=1.5 \times$ SE.

group, versus $71.2 \%, 70.3 \%$, and $66.4 \%$ in the control group (log-rank $P<0.001$; Wilcoxon $P<0.001$; Figure 3 ). If only the 1- to 3-year time interval is considered, the incidence of clinically driven TLR was $4.2 \%$ in the sirolimus group and $1.7 \%$ in the control group $(P=0.45)$, whereas the incidence of TVF was $5.9 \%$ versus $4.3 \%(P=0.77)$, respectively.

\section{Deaths During Follow-Up}

At the end of 3 years, 9 patients had died in the group treated with sirolimus-eluting stents, versus 5 patients in the control group. Six noncardiac deaths occurred in the sirolimus group in the second and third years of follow-up, because of cancer $(n=2)$, intracranial hemorrhage $(n=2)$, respiratory failure $(\mathrm{n}=1)$, and pulmonary embolism $(\mathrm{n}=1)$.

A single patient died of a cardiac cause in the actively treated group 961 days after the stent implantation procedure. The patient was hospitalized because of dyspnea and a cardiac arrhythmia. The patient developed an infection in the hospital that led to kidney failure and septicemia. The patient died 4 days after admission. The Critical Event Committee adjudicated the event as a "cardiac death" because there was insufficient information about the cause of dyspnea and arrhythmia. By contrast, 3 patients died suddenly in the

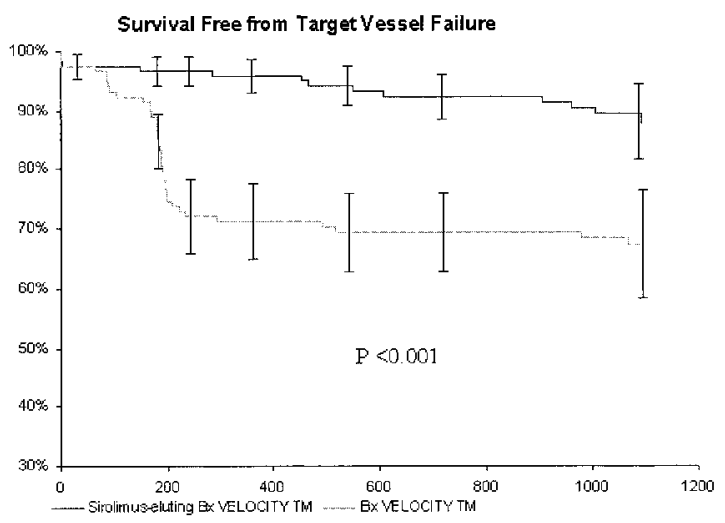

Figure 2. Survival free from TVF in the sirolimus-eluting stent group (dark line) and the control group (shaded line). Error bars $=1.5 \times$ SE. 


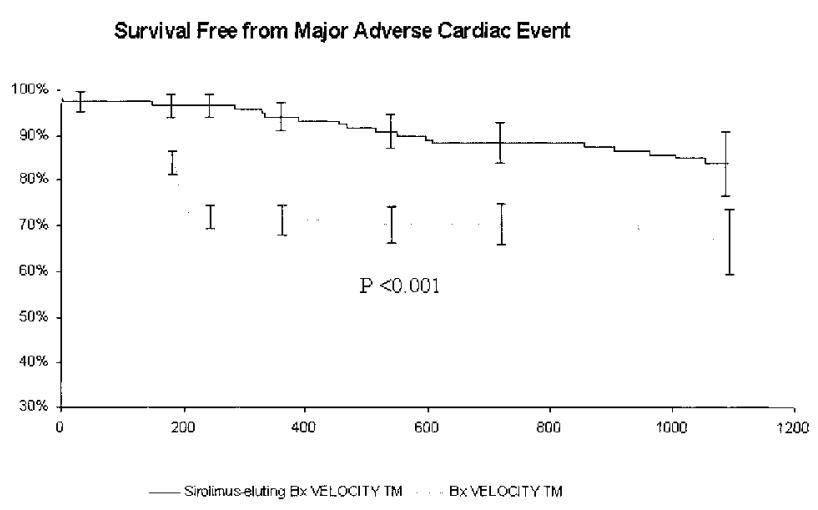

Figure 3. Survival free from MACE in the sirolimus-eluting stent group (dark line) and the control group (shaded line). Error bars $=1.5 \times \mathrm{SE}$.

control group of probable cardiac causes at 45, 517, and 1067 days, respectively, after the index revascularization procedure.

\section{Repeat Revascularization Procedures Between 12 and 36 Months in the Sirolimus-Eluting Stent Group} In the sirolimus-eluting stent group, 3 patients underwent repeat clinically driven revascularization procedures in the second and 3 patients in the third year of follow-up. The first patient, a 68-year-old man, had undergone initial stent implantation for stenosis of the left anterior descending coronary artery (LAD). He developed recurrent angina pectoris at 14 months of follow-up and was found to have a $75 \%$ to $90 \%$ restenosis of the index target lesion (in-stent) and a nearly total occlusion of the right coronary artery. Both stenosis were treated with sirolimus-eluting stents 455 days after the index procedure. The same patient developed recurrent anginal complaints, at which time angiography showed $10 \%$ stenosis with TIMI III perfusion of the target lesion but significant new lesions in the ramus branch, circumflex, and right coronary arteries, which led to bypass surgery, including bypass of the original target lesion, 644 days after the index procedure. The second patient was a 51-year-old man who developed unstable angina and underwent repeat stenting after 468 days for a $70 \%$ in-segment restenosis of the target lesion. The third patient, a 50-year-old man, was initially treated for an LAD stenosis. He presented with recurrent angina and underwent repeat percutaneous coronary revascularization for a $70 \%$ in-segment stenosis at the distal edge of the originally stented lesion at 608 days of follow-up. A second stent was placed in the LAD, overlapping the first stent located in the target lesion. The fourth patient, a 61-year-old man, developed silent ischemia due to a $70 \%$ in-segment restenosis within $5 \mathrm{~mm}$ of the original target lesion in the LAD and underwent repeat percutaneous angioplasty at 904 days of follow-up. A fifth patient underwent multiple coronary artery bypass graft surgery at 1033 days of follow-up 1 month after he had suffered an anteroinferior myocardial infarction, attributed to occlusion of the target vessel. The last patient developed unstable angina 3 years after implantation of a sirolimus-eluting stent in the mid-right coronary artery. He underwent implantation of a second stent for a new $80 \%$ stenosis of the target vessel, outside the original stent, at 1093 days of follow-up.

Finally, one additional patient, a 62-year-old woman enrolled in a RAVEL substudy, underwent a repeat, nonclinically driven, percutaneous revascularization procedure at 551 days of follow-up, after a scheduled diagnostic angiogram was performed at 18 months of follow-up. She had undergone initial stent implantation for treatment of angina pectoris due to a $100 \%$ occlusion of the LAD. The follow-up angiogram showed a $10 \%$ stenosis of the target lesion and an aneurysm in its stented segment. Two additional stents were implanted in the target vessel.

\section{Discussion}

The RAVEL trial was the first randomized, controlled trial to demonstrate that sirolimus delivered from a stent over a 30to 45-day period could virtually eliminate restenosis after angioplasty in patients with de novo coronary atherosclerotic lesions. The very low 1-year rate of target lesion revascularization observed in RAVEL has been corroborated in SIRIUS (Multicenter, Randomized, Double-Blind Study of the Sirolimus-Coated BX VELOCITY Balloon Expandable Stent in the Treatment of Patients With De Novo Native Coronary Artery Lesions), E-SIRIUS, and C-SIRIUS, larger trials that enrolled subsets of patients at considerably higher risk of restenosis than the RAVEL patient population. ${ }^{11-13}$ In light of the observations made during longer-term follow-up in clinical studies of several other antirestenosis agents, ${ }^{16-19}$ it is imperative to demonstrate the absence of both late "catch-up" restenosis and late stent thrombosis when evaluating new strategies aimed at eliminating in-stent restenosis. This is the first randomized, controlled trial of a drug-eluting stent to demonstrate sustained safety and efficacy up to 3 years. These findings, taken in conjunction with the previously reported angiographic and intravascular ultrasound studies of the sirolimus-eluting stents at earlier time points in RAVEL and SIRIUS, ${ }^{10,11}$ and the uncontrolled angiographic and intravascular ultrasound observations made up to 2 years after implantation of sirolimus-eluting stents for de novo coronary stenoses, ${ }^{20,21}$ and up to 1 year after treatment of in-stent restenosis, ${ }^{22}$ confirm that neointimal hyperplasia is effectively suppressed over the long term by sirolimus without interfering with normal reendothelialization. Taken together, these results should dispel the theoretical concerns regarding the long-term biocompatibility of the drug-carrying polymer or other unexpected processes promoting delayed inflammatory, hyperplastic, or thrombotic complications with this particular device.

\section{Main Study Findings}

The major finding of this study is that the highly significant, absolute difference in the need for repeat TLR between patients treated with sirolimus-eluting stents and patients treated with bare-metal stents at 1 year $(23.3 \%)$ remained essentially unchanged at 3 years $(18.7 \%)$. Equally important is the observation that this reduced need for repeat revascularization was not mitigated by an increased risk of short- or long-term fatal or nonfatal cardiovascular events. Although there were more deaths in the sirolimus-eluting stent group, 
all but one were due to noncardiac causes. The difference in target vessel failure, an end point favored by the Food and Drug Administration and the primary end point in the SIRIUS trial, also remained highly significant $(24.6 \%$ at 1 versus $21.4 \%$ at 3 years; $P<0.001$ ). It is also particularly noteworthy that these unprecedented results were obtained with only 2 months of treatment with aspirin plus clopidogrel or ticlopidine and the administration of platelet glycoprotein IIb/IIIa inhibitors in only $10 \%$ of patients.

In contradistinction to these long-term data from RAVEL, the recently published TAXUS IV trial, ${ }^{23}$ with the paclitaxeleluting stent and a different polymer carrier, provides follow-up data to 12-month follow-up. The RAVEL trial is the first large-scale clinical study with a drug-eluting stent reporting long-term follow-up to 3 years. Given the major differences in drugs and polymers being used in different drug-eluting stent systems either already approved or being evaluated, as well as the significant failure of some other systems that have not been approved for sale, it seems prudent to evaluate the long-term outcomes of each new drug-eluting stent system over several years and not assume a class effect.

\section{Limitations of the Study}

Because it is not generally feasible to reevaluate patients serially with invasive procedures, these 3 -year results of the RAVEL trial are limited to clinical end points. The absence of progression of the neointimal hyperplastic process in these patients was, therefore, inferred rather than directly ascertained by angiography or intravascular ultrasound. However, the meticulous observations made in 45 patients who underwent both angiography and intravascular ultrasound up to 2 years in the FIM trial suggest that this assumption is legitimate. ${ }^{20-22}$

\section{Conclusions}

The remarkable safety and efficacy of sirolimus-eluting stents, documented angiographically and by intravascular ultrasound at 6 months after device implantation in this trial, were confirmed clinically up to 3 years after device implantation.

\section{Acknowledgment}

This trial was sponsored by Cordis Corporation, a Johnson \& Johnson Company, Warren, NJ. The authors thank Rodolphe Ruffy, MD, Dennis Donohoe, MD, and Brian Firth, MD, PhD, for their assistance in the preparation of this manuscript.

\section{References}

1. Babapulle MN, Eisenberg MJ. Coated stents for the prevention of restenosis, II. Circulation. 2002;106:2859-2866.

2. Marx SO, Marks AR. Bench to Bedside. The development of rapamycin and its application to stent restenosis. Circulation. 2001;104:852-855.

3. Marx SO, Jayaraman T, Go LO, Marks AR. Rapamycin-FKBP inhibits cell cycle regulators of proliferation in VSMC. Circ Res. 1995;76: 412-417.

4. Poon M, Marx SO, Gallo R, Badimon JJ, Taubman MB, Marks AR. Rapamycin inhibits vascular smooth muscle cell migration. J Clin Invest. 1996;98:2277-2283.

5. Burke SE, Lubbers NL, Chen Y-W, Hsieh GC, Mollison KW, Luly JR, Wegner CD. Neointimal formation after balloon-induced vascular injury in Yucatan minipigs is reduced by oral rapamycin. $J$ Cardiovasc Pharmacol. 1999;33:829-835.
6. Gregory CR, Huang X, Pratt RE, Dzau VJ, Shorthouse R, Billingham $\mathrm{ME}$, Morris RE. Treatment with rapamycin and mycophenolic acid reduces arterial intimal thickening produced by mechanical injury and allows endothelial replacement. Transplantation. 1995;59:655-661.

7. Gallo R, Padurean A, Jayaraman T, Marx S, Roque M, Adelman S, Chesebro J, Fallon J, Fuster V, Marks A, Badimon JJ. Inhibition of intimal thickening after balloon angioplasty in porcine coronary arteries by targeting regulators of the cell cycle. Circulation. 1999;99: 2164-2170.

8. Suzuki T, Kopia G, Hayashi S, Bailey LR, Llanos G, Wilensky R, Klugherz BD, Papandreou G, Narayan P, Leon MB, Yeung AC, Tio F, Tsao PS, Falotico R, Carter AJ. Stent-based delivery of sirolimus reduces neointimal formation in a porcine coronary model. Circulation. 2001; 104:1188-1193.

9. Sousa JE, Costa MA, Abizaid AC, Rensing BJ, Abizaid AS, Tanajura LF, Kozuma K, Van Langenhove G, Sousa AG, Falotico R, Jaeger J, Popma JJ, Serruys PW. Sustained suppression of neointimal proliferation by sirolimus-eluting stents: one-year angiographic and intravascular ultrasound follow-up. Circulation. 2001;104:2007-2011.

10. Morice M-C, Serruys PW, Sousa JE, Fajadet J, Ban Hayashi E, Perin M, Colombo A, Schuler G, Barragan P, Guagliumi G, Molnar F, Falotico R, RAVEL Study Group. A randomized comparison of a sirolimus-eluting stent with a standard stent for coronary revascularization. $N$ Engl J Med. 2002;346:1773-1780.

11. Moses JW, Leon MB, Popma JJ, Fitzgerald PJ, Holmes DR, O'Shaughnessy C, Caputo RP, Kereiakes DJ, Williams DO, Teirstein PS, Jaeger JL, Kuntz RE, SIRIUS Investigators. Sirolimus-eluting stents versus standard stents in patients with stenosis in a native coronary artery. $N$ Engl J Med. 2003;349:1315-1323.

12. Schofer J, Schluter M, Gershlick AH, Wijns W, Garcia E, Schampaert E, Breithardt G, E-SIRIUS Investigators. Sirolimus-eluting stents for treatment of patients with long atherosclerotic lesions in small coronary arteries: double-blind, randomised controlled trial (E-SIRIUS). Lancet. 2003;362:1093-1099.

13. Schampaert E, Cohen EA, Schluter M, Reeves F, Traboulsi M, Title LM, Kuntz RE, Popma JJ, C-SIRIUS Investigators. The Canadian study of the sirolimus-eluting stent in the treatment of patients with long de novo lesions in small native coronary arteries (C-SIRIUS). J Am Coll Cardiol. 2004;43:1110-1115.

14. Campeau L. Grading for angina pectoris [letter]. Circulation. 1976;54: 522-523.

15. Braunwald E. Unstable angina: a classification. Circulation. 1989;80: 410-414.

16. Albiero R, Nishida T, Adamian M, Amato A, Vaghetti M, Corvaja N, Di Mario C, Colombo A. Edge restenosis after implantation of high-activity ${ }^{32} \mathrm{P}$ radioactive $\beta$-emitting stents. Circulation. 2000;101:2454-2457.

17. Costa MA, Sabate M, van der Giessen WJ, Kay IP, Cervinka P, Ligthart JM, Serrano P, Coen VL, Levendag PC, Serruys PW. Late coronary occlusion after intracoronary brachytherapy. Circulation. 1999;100:789-792.

18. Grube E, Hauptmann K, Colombo A, DiSciascio G, Silber S, Bach R, DiMario C, Reifart N, Fajadet J, Score Investigators. SCORE trial interim safety results: despite efficacy, late stent thrombosis with the QuaDDS-QP2 stent. J Am Coll Cardiol. 2002;39(suppl A):38A. Abstract.

19. Liistro F, Colombo A. Late acute thrombosis after paclitaxel eluting stent implantation. Heart. 2001;86:262-264.

20. Sousa JE, Costa MA, Sousa AG, Abizaid AC, Seixas AC, Abizaid AS, Feres F, Mattos LA, Falotico R, Jaeger J, Popma JJ, Serruys PW. Two-year angiographic and intravascular ultrasound follow-up after implantation of sirolimus-eluting stents in human coronary arteries. Circulation. 2003;107:381-383.

21. Degertekin M, Serruys PW, Foley DP, Tanabe K, Regar E, Vos J, Smits PC, van der Giessen WJ, van den Brand M, de Feyter P, Popma JJ. Persistent inhibition of neointimal hyperplasia after sirolimus-eluting stent implantation: long-term (up to 2 years) clinical, angiographic, and intravascular ultrasound follow-up. Circulation. 2002;106:1610-1613.

22. Sousa JE, Costa MA, Abizaid A, Sousa AG, Feres F, Mattos LA, Centemero M, Maldonado G, Abizaid AS, Pinto I, Falotico R, Jaeger J, Popma JJ, Serruys PW. Sirolimus-eluting stent for the treatment of in-stent restenosis: a quantitative coronary angiography and threedimensional intravascular ultrasound study. Circulation. 2003;107: $24-27$.

23. Stone GW, Ellis SG, Cox DA, Hermiller J, O'Shaughnessy C, Mann JT, Turco M, Caputo R, Bergin P, Greenberg J, Popma JJ, Russell ME, TAXUS-IV Investigators. A polymer-based, paclitaxel-eluting stent in patients with coronary artery disease. N Engl J Med. 2004;350:221-231. 